\title{
Parametric Analysis of Hyperbolic Cooling Tower under Seismic Loads, Wind Loads and Dead Load through Staad. Pro
}

\author{
Akash Goyal ${ }^{1}$, A N Shankar ${ }^{2}$, S K Sethy ${ }^{3}$ \\ ${ }^{1}$ M.tech Student: Structural Engineering with Specialization in Offshore Structures, University of Petroleum and Energy \\ Studies, Dehradun India. \\ ${ }^{2,3}$ Asst. Professor Civil Engineering Department U.P.E.S, Dehradun
}

\begin{abstract}
Hyperbolic cooling towers are large, thin shell reinforced concrete structures which contribute to environmental protection and to power generation efficiency and reliability. The safety of hyperbolic cooling towers is important to the continuous operation of a power plant. It is observed from the analysis that maximum displacement, support reactions, support moments, stresses and bending moments in plates due to seismic loading, wind loading and dead load i.e. its self weight on a hyperbolic cooling tower is continuous function of geometry (top diameter, throat diameter and height). Earthquake zone plays the important role in analysis. So from this work it can be observed that $300 \mathrm{~mm}$ thickness, throat diameter $60 \mathrm{~m}$ and height $250 \mathrm{~m}$ is much efficient among all but if height is mandatory to extent than height should not be more than $159 \mathrm{~m}$ (height taken from actual work) and $170 \mathrm{~m}$ height is critical.
\end{abstract}

Keywords-Cooling tower, node displacement, support reactions, plate stresses.

\section{INTRODUCTION}

Cooling tower is a tall cylindrical concrete tower used for cooling water or condensing steam from an industrial process. It is a heat rejection device which extracts waste heat to the atmosphere through the cooling of a water stream to a lower temperature. It is generally of 2 shapes, hyperboloid or hyperbolic and rectangular. Hyperboloid cooling towers will be around $130-200 \mathrm{~m}$ tall and $100 \mathrm{~mm}$ in diameter while the rectangular cooling towers will be around $40 \mathrm{~m}$ tall and $80 \mathrm{~m}$ long. Cooling tower is generally made of concrete and rebar. The type of foundation required for each cooling tower, e.g. individual foundations, ring foundation or piling, is determined according to the ground conditions. Applications of cooling tower include Oil refineries, petrochemical and other chemical plants, thermal power stations and HVAC systems for cooling buildings. The safety of hyperbolic cooling towers is important to the continuous operation of a power plant. Depending upon the site, earthquake may govern the design of the tower.

\section{Classification OF COOLING TOWERS}

Cooling towers can generally be classified by it's

Use:

- $\quad$ Build

- Heat Transfer methods

- Air flow generation methods

Classification by Use:

Heating, Ventilation and Air Condition (HVAC) Cooling towers.

\section{A. Shape of a Cooling Tower}

Cooling towers are generally of 2 shapes, hyperboloid or hyperbolic and rectangular. Rectangular cooling towers are generally small in size which are associated with small buildings such as residential buildings, small industries etc. Height of a rectangular cooling tower will be around $40-80 \mathrm{~m}$. In this study, 4 cooling towers of height $150 \mathrm{~m}, 200 \mathrm{~m}, 250 \mathrm{~m}$ and $300 \mathrm{~m}$ with three different plate thicknesses of $200 \mathrm{~mm}, 250 \mathrm{~mm}$ and $300 \mathrm{~mm}$ were modelled using STAAD Pro software. The radius of throat and base diameters were also varied according to different models. These models were analysed for wind load as well as seismic loads. Equivalent static analysis and Response Spectrum analysis were carried out for seismic loads. Nodal displacement, support reactions, mode shapes, base shear and plate stress of the models were compared and the optimum height of the plate and thickness of the plate were obtained. The critical plate was designed manually. 


\section{MODELLING}

Modelling a building involves the modelling and assemblage of its various load carrying elements. The model must ideally represent the mass distribution, strength, stiffness and deformability. The first part of this chapter gives a summary of various parameters such as material properties, basic geometry required to define the model. Accurate modelling of the nonlinear properties of various structural elements is very important in nonlinear analysis. In this study, STAAD Pro v8i is used for the modelling and analysis of the structure.

\subsection{Details of Modelling}

The modelling of the structure is done in STAAD Pro. Four models of heights $150 \mathrm{~m}, 200 \mathrm{~m}, 250 \mathrm{~m}$ and $300 \mathrm{~m}$ were modelled and each model was assigned with three different thicknesses $200 \mathrm{~mm}, 250 \mathrm{~mm}$ and $300 \mathrm{~mm}$ for the concrete plates used in the model. The models were analysed for both wind load as well as seismic load. The top edge of the cooling tower is free to translate and rotate in all directions, while the base is completely fixed.

\subsection{Structural Details of the Models}

The structural details of four different models created are given in Table1

\section{TABLE 1}

STRUCTURAL DETAILS OF THE MODELS

\begin{tabular}{|c|c|c|c|c|c|}
\hline S. No & Parameters $(\mathbf{m})$ & Model 1 & Model 2 & Model 3 & Model 4 \\
\hline 1. & Height & 150 & 200 & 250 & 300 \\
\hline 2. & Base diameter & 118 & 115 & 110 & 105 \\
\hline 3. & Top diameter & 60 & 65 & 70 & 90 \\
\hline 4. & Throat diameter & 40 & 50 & 60 & 80 \\
\hline
\end{tabular}

\section{Material Properties}

This section provides the properties of the material used for the modelling of the cooling tower. Reinforced concrete with a unit weight of $25 \mathrm{kN} / \mathrm{m} 3$, Poisson's ratio of 0.2 , damping ratio of $5 \%$ and elastic modulus of $39 \mathrm{GPa}$ were considered for the finite-element modelling of the cooling tower.

\subsection{Loading}

Dead load, wind load and seismic load were applied on the structure. Dead load shall be calculated on the basis of the unit weights taken in accordance with IS: 875 (part 1)-1987. Wind loads shall be taken as specified in IS: 875 (part 3)1987. Seismic load shall be taken in accordance with IS: 1893 (part 1)-2002. The instances where concentrated loads occur, special consideration should be given in analysis and design. Dynamic loads of interest include wind loads and seismic actions that are time dependent and asymmetric. The use of equivalent static loads simplifies the analysis, however, it does not account for interaction between the frequencies of the applied load and the characteristic natural frequencies of the structure and limited knowledge on the dynamic behavior of structure. Parameters that are considered for wind loading according to IS875-Part 3 details are given in Table 2.

TABLE 2

WIND LOAD PARAMETERS

\begin{tabular}{|c|c|c|}
\hline S. No. & Parameters & Value \\
\hline 1 & Basic wind speed $\left(\mathrm{V}_{\mathrm{b}}\right)$ & $39 \mathrm{~m} / \mathrm{sec}$ \\
\hline 2 & Probability factor/Risk coefficient $\left(\mathrm{K}_{1}\right)$ & 1.06 \\
\hline 3 & Terrain roughness and height factor $\left(\mathrm{K}_{2}\right)$ & 2 \\
\hline 4 & Topography factor $\left(\mathrm{K}_{3}\right)$ & 1 \\
\hline 5 & Exposure of Building & $100 \%, 1$ \\
\hline
\end{tabular}




\subsection{Earthquake Loads}

Parameters for Earth quake loads according to IS 18932002 (Part 2) are given in Table 3.

TABLE 3

SEISMIC LOAD PARAMETERS

\begin{tabular}{|c|c|c|}
\hline S. No. & Parameters & Value \\
\hline 1 & Zone & 4 \\
\hline 2 & Zone Factor & 5 \\
\hline 3 & Response reduction factor (RF) & 1.5 \\
\hline 4 & Importance factor (I) & 24 \\
\hline 5 & Soil Type(SS), Medium soil & $5 \%, .05$ \\
\hline 6
\end{tabular}

\section{RESULT}

12 different models were analyzed for wind load and seismic loads. Seismic analyses included equivalent static analysis and response spectrum analysis. Maximum nodal displacement, support reactions and stress for each case was determined and compared to study the impact of the different load conditions for varying height and thickness of plate in a simulated model. Table 4 shows the maximum node displacements for wind load for the cooling tower model of height and table 5 shows the Support Reactions of all the models $150 \mathrm{~m}$ and varying plate thicknesses of $200 \mathrm{~mm}, 250 \mathrm{~mm}$ and $300 \mathrm{~mm}$.

TABLE 4

MAXIMUM NODE DISPLACEMENTS FOR WIND LOAD

\begin{tabular}{|c|c|c|}
\hline S. No & Thickness of plate $(\mathbf{m m})$ & Maximum Displacement (mm) \\
\hline 1. & 200 & 67.314 \\
\hline 2. & 250 & 51.903 \\
\hline 3. & 300 & 42.049 \\
\hline
\end{tabular}

TABLE 5

SUPPORT REACTIONS OF ALL THE MODELS

\begin{tabular}{|c|c|c|c|c|}
\hline Height $(\mathbf{m})$ & Thickness $(\mathbf{m m})$ & Wind $(\mathbf{K N})$ & ESA (KN) & RSA (KN) \\
\hline 150 & 200 & 3257.11 & 3328.09 & 9106.94 \\
\hline 150 & 250 & 2943.79 & 2961.63 & 4666.53 \\
\hline 150 & 300 & 2642.87 & 2092.01 & 3975.45 \\
\hline 200 & 200 & 2786.046 & 2557.472 & 3005.85 \\
\hline 200 & 250 & 2564.103 & 2208.38 & 3903.43 \\
\hline 200 & 300 & 2350.066 & 1850.23 & 4686.75 \\
\hline 250 & 200 & 2458.526 & 1700.575 & 2246.26 \\
\hline 250 & 250 & 2304.855 & 1461.078 & 2997.58 \\
\hline 250 & 300 & 2153.708 & 1216.747 & 3510.014 \\
\hline 300 & 200 & 3228.64 & 2020.508 & 2840.05 \\
\hline 300 & 250 & 3022.091 & 1729.904 & 3547.5 \\
\hline 300 & 300 & 2820.721 & 1434.257 & 4145.81 \\
\hline
\end{tabular}




\section{CONCLUSION}

From the analysis results, it can be concluded that

- The nodal displacement of the structure increases by $30 \%$ as the height of the Cooling tower is increased while the nodal displacement can be reduced by around $20-25 \%$ by increasing the thickness of the plate used for modelling the cooling tower.

- Mass participation of more than $75 \%$ is obtained for all the dominant modes.

- The variation in plate stress was found to be minimum (5\%) with the increase in height of the model and thickness of the plate.

- $\quad$ The CQC shear of the increased by around $35 \%$ as the height of the tower and thickness of the plate is increased.

From the above results taking cost effectiveness into consideration, the optimum height for a cooling tower can be considered as $250 \mathrm{~m}$, optimum plate thickness as $300 \mathrm{~mm}$ and optimum throat diameter as $60 \mathrm{~m}$.

\section{REFERENCES}

[1]. IS 1893 (Part 2\&3): 2002,” Criteria for Earthquake Resistant Design of Structures”, Bureau of Indian Standards, New Delhi.

[2]. IS 11504-1985, Criteria for structural design of RCC natural draft cooling towers, BIS new Delhi.

[3]. Seismic analysis and design of hyperbolic cooling tower by A.K.GUPTA, Sergeant and Lundy, Chicago Illinois 60603 USA. Pg 110.

[4]. IS: 875(Part3): Wind Loads on Buildings and Structures

[5]. Parametric Earthquake Analysis of Natural Draught Hyperbolic Cooling Tower by Akhil Nema, K. K. Pathak NITTTR Bhopal.

[6]. Static and dynamic analysis of structures" A physical approach with emphasis on earthquake engineering, Pg 111-225. 